DOI: 10.31862/2500-297X-2019-3-30-42

\title{
Т.А. Челнокова
}

Казанский инновационный университет им. В.Г. Тимирясова, 420111 г. Казань, Российская Федерация

\section{Техники визуализации \\ и их актуальность \\ в организации работы \\ с учебной информацией современных ШкольникОв}

В статье дается описание разнообразных техник визуализации учебного материала, обосновываются их возможности. Аргументируя ценность техник визуализации, автор учитывает современные требования к образованию и дает свое видение возможностей данных техник (в том, числе являющихся элементами интерактивных технологий обучения) в решении образовательных задач. Содержание статьи построено на основе исторического анализа теории и практики визуализации процесса учения с элементами сравнительно-сопоставительного анализа его реализации в отечественной школе. Актуализируя собственный опыт и опыт коллег, автор дает свое видение современной практики визуализации работы обучающихся с учебной информацией, которая осуществляется с учетом процесса компьютеризации образования, приоритетом групповых форм работы учащихся. Автор приводит теоретико-методологические идеи, которые могут быть взяты за основу концептуального обоснования визуализации процесса учения.

Ключевые слова: техники визуализации, учебная информация, интерактивные технологии обучения, сенсорные анализаторы, опорные сигналы, инографика, метод синектики, наглядно-образное мышление

ССЫЛКА НА СТАТЬЮ: Челнокова Т.А. Техники визуализации и их актуальность в организации работы с учебной информацией современных школьников // Педагогика и психология образования. 2019. № 3. C. 30-42. DOI: 10.31862/2500297X-2019-3-30-42 


\section{T. Chelnokova}

Kazan Innovative University named after V.G. Timiryasov, Kazan, 420111, Russian Federation

\section{Visualization techniques and their applicability in arranging the work of modern scholar with educational information}

The article describes a variety of visualization techniques for educational material and substantiates their potential. Arguing the value of visualization techniques, the author takes into account modern requirements for education and gives her vision of the capabilities of these techniques (including those that are elements of interactive learning technologies) in solving educational problems. The content of the article is based on a historical analysis of the theory and practice of visualizing the learning process with elements of a comparative analysis of its implementation in schools of our country. Actualizing her own experience and the experience of her colleagues, the author gives her vision of the modern practice on visualization of the students' work with the educational information which is implemented with consideration of the education computerizing process, with priority of the team forms of students' work. The author gives theoretical and methodological ideas that can be taken as the basis for the conceptual substantiation of the visualization of the learning process.

Key words: visualization techniques, educational information, interacting techniques of education, sensor analyzers, reference signals, infographic, synectics method, eye-mindedness

CITATION: Chelnokova T.A. Visualization techniques and their applicability in arranging the work of modern students with educational information. Pedagogy and Psychology of Education. 2019. No. 3. Pp. 30-42. DOI: 10.31862/2500297X-2019-3-30-42 
Приоритетным требованием к организации современного образования выступает формирование у обучающихся навыков и умений, необходимых для работы с информацией, для социальных коммуникаций. В качестве основного инструмента реализации настоящего требования обозначены технологии интерактивного обучения, внедрение которых должно изменить роль обучающегося в процессе учебного взаимодействия, сделать его субъектом образовательных отношений. Однако ориентация на деятельностное развитие личности, результатами которого выступают приобретенные умения и навыки (познавательные, социальнокоммуникативные, художественно-эстетические и т.п.), не снижает ценность самой информации. При этом возрастающий поток информации требует новых подходов для организации работы с ней современного школьника.

В поиске новых техник работы обучающихся с информацией необходимо диалектическое осмысление теоретических воззрений прошлого и опыта их реализации в практике обучения. Не менее актуальным является формирование концептуальных основ педагогической деятельности в построении новой модели работы обучающихся с информацией. Умение работать с информацией - одно из общеучебных умений. В качестве компонентов этого умения О.А. Митрахович называет поиск, анализ, интерпретацию, сохранение информации и т.д. [7, с. 9]. Делая акцент на сохранении информации в памяти обучающегося как условия ее осмысления, анализа, обобщения, необходимо определить и описать техники, использование которых в процессе обучения сделает информационные знания более доступными, лучше сохраняемыми без увеличения перегрузки на механизмы памяти. В этой связи все больший интерес у теоретиков и практиков вызывают техники визуализации.

Я.А. Коменский, который считается основателем матетики, науки (искусства, техники) учиться, отмечал непосредственную роль чувств для «восприятия вещей в Мире», называя чувства самыми первыми и надежными инструментами человеческого познания [6]. Принцип наглядности обучения в течении многих лет истории оставался основным принципом не только системы школьного образования. Активизация зрительных, слуховых, тактильных анализаторов (по Я.А. Коменскому, «увидеть, услышать, пощупать») в постижении не только предметов и явлений, но и действий с ними было одним из важнейших требований к организации обучения. За организацию обучения таким образом, чтобы были задействованы органы чувств, выступали К.Д. Ушинский, В.П. Вахтерев и многие другие представители педагогической науки, обосновывавшие свое видение роли наглядности в обучении ребенка. В.П. Вахтерев писал, что в познавательной деятельности 
присутствуют одновременно ум, чувства и воля, «три взаимосвязанных звена одной цепи, “три силы в одном соединении” ... главенствующая роль всегда принадлежала первой из этих сил - уму» [1, с. 19].

В соответствии с принципом наглядности обучения и учебными программами разрабатывались наглядные пособия, с опорой на которые объяснялся и закреплялся изучаемый материал. Через деятельность сенсорных анализаторов и наглядно-действенное мышление осваивались азы знаний многими поколениями обучающихся. При этом были задействованы не только зрительные, но и двигательные анализаторы (движение глаз, рук).

Для визуализации текстов литературных произведений, событий истории или явлений природы использовались технические средства обучения (ТСО). Фильмоскопы, диапроекторы, кинопроекторы, кодоскопы широко применялись в 1970-1980-е гг., помогая учителю познакомить учащихся с информацией, облегчая процесс ее запоминания, применения и понимания. В 1990-е гг. на помощь педагогу приходит телевидение, на котором появляются программы по учебным предметам. Видеоурок становится новой формой взаимодействия обучающегося с учебной информацией. Таким образом, если обратиться к прошлому российского образования, можно увидеть последовательное включение в процесс учения сенсорных (в первую очередь зрительных) анализаторов обучающихся благодаря применению соответствующих временному периоду средств обучения.

В условиях цифрового общества, когда компьютерные программы и аппаратные устройства становятся постоянным спутником человека, появляются новые возможности активизации деятельности сенсорных анализаторов в работе с учебной информацией. При этом работа зрительных анализаторов в освоении знаний сохраняет некую приоритетность. В книге Л. Грегори «Глаз и мозг», вышедшей еще в 1970-е гг., автор отмечает преимущество зрительного восприятия над слуховым [4]. В эпоху смартфонов это преимущество сохраняется, предопределяя актуальность методов визуализации в обучении современного школьника.

В контексте происходящих перемен в системе образования, функционирующей в информационно-знаниевую эпоху, разрабатываются и внедряются новые техники визуализации учебной информации. Многие из них становятся доступными благодаря компьютеризации образовательного процесса. Обосновывая преимущество визуализации в обучении, О.Г. Сорока и И.Н. Васильева называют следующие техники: таймлан (в буквальном переводе с английского - «линия времени»); интеллект-карта (графическое представление информации); скрайбинг 
(визуализация учебной информации с помощью графических символов); инфографика - подача информации с возможным применением таблиц, графиков и т.п. [10]. Важнейшим преимуществом данных техник является то, что они не только предоставляют визуальное оформление изучаемого материала, но и включают в действие механизмы второго, по мнению Я.А. Коменского, источника познания - Рассудка.

Современные исследователи стремятся выявить и обосновать возможности техник визуализации в оптимизации процессов взаимодействия обучающихся с учебной информацией. В качестве значимой детерминанты визуализации учебного материала многие из них называют большой объем информации, который должен быть осмыслен обучающимся, и положительно оценивают «представление учебного материала в графически структурированном виде» для быстрого и качественного усвоения новых знаний [12, с. 77]. Особенностью современных техник визуализации учебного материала является использование разнообразных символов. Знаково-символические структуры визуализации учебного материала позволяют уплотнить и пошагово развернуть изучаемый материал.

Как и многие другие новообразования, современные техники визуализации возникают не на пустом месте. Родоначальником символических структур визуализации можно считать педагога-новатора 1970-х гг., донецкого учителя В.Ф. Шаталов. В своей книге «Педагогическая проза» он представляет методику обучения, важнейшим элементом которой являются опорные сигналы. Обосновывая возможности опорных сигналов в решении задач обучения, В.Ф. Шаталов отмечает их преимущество: облегчать «ребятам процесс запоминания и воспроизведения» информации; определять «рамки ответа каждого ученика во время устного ответа» $[13$, с. 11$]$.

Визуализация учебного материала, по В.Ф. Шаталову, структурировалась в виде символов (слов, рисунков, стрелок, знаков), их перерисовывание в тетради и озвучивание имело большое значение для осмысления учениками изучаемой информации.

В течение многих лет автор данной статьи активно использовал идеи В.Ф. Шаталова в преподавании истории. Личный опыт, с учетом мнения бывших учеников, позволяет высоко оценить опорные конспекты, опорные схемы (сигналы - по В.Ф. Шаталову) в оптимизации работы школьников с информацией. Опорные конспекты составлялись по теме события, на изучение которого выделялось большое количество часов. Опоры позволяли визуально сузить объем информации, которую предстояло изучить. Учебная информация последовательно конкретизировалась, уточнялась, расширялась в процессе прохождения темы, при этом 
визуальное присутствие опоры способствовало лучшему закреплению знаний в памяти учеников. Ценность опорных конспектов была и в том, что они позволяли объединить материал в единое целое, обозначить причинно-следственные связи, выделить ключевые понятия. Системность работы над опорным конспектом позволяла достигнуть лучших результатов в понимании обучающимися целостности изучаемого события и закономерных тенденций его развития.

Опорные схемы (сигналы) составлялись по темам параграфов. В практике собственной педагогической деятельности были отработаны разнообразные формы работы с ними:

- создание опорной схемы учителем на доске в процессе работы над темой параграфа с параллельной зарисовкой ее элементов учащимися; - оформление опорной схемы на карточках в качестве дидактического материала урока для организации самостоятельной работы школьников с текстом нового параграфа и опорой с последующим уточнением педагогом системы обозначения и отраженного в них содержания; - работа учащихся с опорными схемами в парах с целью проверки и коррекции усвоенных одноклассником знаний.

Осмысливая построенный на основе опорных конспектов (схем) процесс взаимодействия обучающихся с учебной информацией, можно выделить:

- активизацию деятельности зрительных анализаторов, чему особо способствует использование цвета, рисунков-символов;

- улучшение качества слухового восприятия информации благодаря ее дозированию и возвращению внимания учащихся к ранее озвученному и уже включенному в опору;

- активизацию двигательных анализаторов при перерисовывании опор в тетради, проговаривании значения символов;

- облегчение восприятия информации благодаря позитивному эмоциональному фону подачи материала.

Таким образом, использование опорных конспектов (схем, сигналов) значительно расширяет возможности обучающихся к восприятию, запоминанию и осмыслению изучаемой информации. И хотя уровень глубины развития данных процессов зависит от индивидуальных способностей обучающегося, мотивов учения, можно, несомненно, признать достигаемые результаты как позитивные. Предназначение опор не столько в сохранении определенных объемов информации в памяти обучающихся, сколько ее осмысление и восстановление для установления связей между пройденным и новым материалом. Один из сторонников матетики как науки об учении XX в. С. Пайперт отмечал особую важность при изучении нового «найти связь (нового) с чем-либо уже 
известным» [11, с. 10]. Опорные конспекты, сигналы позволяют визуально сфокусировать взор учащихся на главном, тем самым сопутствуя осмыслению изучаемого явления.

Цифровая эпоха значительно расширяет возможности визуализации учебной информации, благодаря техническим устройствам современные опоры могут быть более зрелищными, привлекая и удерживая внимание обучающихся. Они могут быть активно использованы для формирования понятийного строя учебной дисциплины, что имеет большое значение для осмысления изучаемых явлений, логики их развития.

Визуализация учебной информации на основе опор присутствует в технологиях интерактивного обучения. В частности, среди стратегий (приемов) технологии Развития критического мышления средствами чтения и письма (РКМСЧиП) - стратегия кластер. (Технология возникла в конце XX в. в США, в основе ее лежат идеи Ж. Пиаже, Л.С. Выготского, К. Поппера, Р. Пола.) Согласно стратегии кластер, при работе с текстом (возможны индивидуальная, парная и групповая формы работы) обучающиеся выделяют: ключевую единицу текста в форме слова или словосочетания; смысловые единицы (категории информации), связанные с ключевым понятием; конкретизацию информации в фактах, цифрах.

В технологии ТРИЗ (теория решения изобретательских задач) техника визуализации учебного материала в виде опорной схемы выстраивается в соответствии с идеей воспитания Решателя, а создание опорной схемы (сигнала) может выступать как один из видов деятельности учащихся (например, как вариант домашнего задания) [3].

Схема визуализации изучаемого материала в технологии педагогических мастерских Французской группы нового образования (ЖФЕН) была представлена российским педагогам в 1990-е гг. [9]. Идеи технологии зародились в 1920-е гг,, тесным образом перекликаясь с идеями Д. Дьюи и его сторонников, которые, в свою очередь, нашли отражение в практике российского образования как бригадный метод обучения, рекомендованный к внедрению в 1929 г. Наркомпросом РСФСР. Технология педагогических мастерских получила концептуальное обоснование и широкое распространение в 1990-е гг., практика ее реализации в отечественной школе нашла отражение в диссертационных исследованиях [8]. Технология хорошо вписывается в современные требования к организации учебной деятельности (стимулирование (индукция) учебной деятельности; роль педагога на уроке - роль фасилитатора, групповая работы учащихся над созданием нового продукта, равенство всех и т.д.). Технология предполагает самостоятельную работу обучающихся с текстом, согласно заданному педагогом алгоритму действий. Коллективным продуктом учебной деятельности может быть 
схематизированное представление изучаемого текста на листе ватмана с использованием в оформлении иллюстраций. Возможны и другие варианты визуализации, например, выделение ключевых понятий каждого фрагмента текста с занесением их на чистый лист бумаги с использованием символов и определением линии связи в ходе этапа афиширования (один из этапов мастерских). Оформление презентации (или ее проекта) к изучаемому тексту - еще один вариант работы групп.

Три приведенных выше варианта визуализации изучаемой информации демонстрируют особенности включения сенсорных анализаторов (не только зрительных, но и слуховых, двигательных и даже тактильных) обучающихся в работу с информацией. Такое включение, сохраняя ценность чувственного познания в учении, отвечает требованиям современности и строится на основе личностной активности обучающихся (познавательной, социальной, физической), соответствуя модели интерактивного обучения.

Сколь бы не различны были описанные выше техники визуализации учебной информации по средствам обучения (гербарии, таблицы, наглядные пособия, видеоматериалы и т.д.), по методам их применения в организации взаимодействия школьников с информацией (создаются педагогом, создаются учащимися), все они выстраиваются на основе материализованных форм наглядности. Однако в педагогической теории имеется описание использования воображаемых образов исследуемых объектов и явлений. Собственный опыт автора статьи позволяет позитивно оценить возможности техник визуализации, построенных на образно-чувственном мышлении, интуиции, творческом воображении, в глубинном освоении содержания учебного материала.

Одним из вариантов техники визуализации, построенной на основе ассоциативного мышления, является метод синектики, разработанный У. Гордоном в 1948 г. Метод позволяет мысленно «визуализировать» невидимое через видимое, незнакомое через знакомое на основе следующих механизмов превращения: личностная аналогия, прямая аналогия, символическая аналогия, фантастическая аналогия. Метод синектики был представлен педагогическому сообществу нашей страны благодаря работам М.В. Кларина [5]. Актуализация метода синектики автором статьи в педагогической деятельности позволяет отметить вариативность организационных форм его применения в изучении учебного материала школьниками. Представим некоторые варианты учебных заданий в изучении истории и обществознания, составленных на основе метода синектики.

1. Учащимся предлагается сравнить отношения общества и личности на примере представленных их зрению вариантов различных растений 
(бурно цветущих и увядающих, с иголками и листвой и т.п.) в цветочных горшках, которые тоже отличаются размером, состоянием и т.п.

2. Интегрированный урок химии и истории - учитель химии демонстрирует химические реакции, уже известные школьникам, в ходе беседы с ними составляется схема классификации химических реакций с описанием основных признаков для каждого вида (реакция соединения, замещения, разложения). Работая по данной схеме, учитель истории, снимая термин «химическая», просит переводит значение термина «реакция» в ракурс исторических событий (варианты могут быть разные - николаевская реакция, крестьянская война, революция и т.п.). В беседе проводится параллель между химическими и историческими процессами (например, аналогия реакции замещения - смена правителей в Смутное время). В аналогии с курсом химии, благодаря проводимым опытам, задействуются многие анализаторы, позволяющие лучше прочувствовать прошлое.

3. Индивидуальная, парная, групповая работа, связанная с проведением аналогий между рисунками и фактами, понятиями, явлениями (возможно заранее определенная параллель аналогий: автомобиль - государство).

Более детально описание использования символической аналогии в изучении истории дается в одной из наших работ [14]. Наиболее эффективным, на наш взгляд, является использование метода синектики для обобщения пройденного, когда первичный блок информации уже заложен в памяти обучающегося и необходимо дать ей более осмысленное понимание.

Опыт использования метода синектики в обучении в качестве своеобразной формы символической визуализации позволяет выделить некоторые сложности в его применении. В первую очередь они связаны со стереотипностью мышления, неумением школьников выключить все ограничители мысли (правильно - неправильно). Поэтому процесс проведения ассоциаций между знакомым и незнакомым должен быть целенаправленно выстроен педагогом, в последовательном соблюдении традиционных принципов дидактики (например, от простых форм аналогий к более сложным).

Свой потенциал для визуализации уже изученных событий, явлений и фактов имеет техника образно-чувственной визуализации. В течение нескольких лет в работе со школьниками мы апробировали идеи А.А. Вострикова о формах и методах педагогической деятельности в развитии культуры чувств и эмоций и включении их в процесс работы с информацией. Согласно идеям А.А. Вострикова, сформированным 
на основе концептуального осмысления трудов отечественных и зарубежных психологов, восточных техник, методика развития образно-чувственного мышления - это процесс превращения словесного в образное (зрительное, слуховое, вкусовое, обонятельное, тактильное); создания воображаемых действий, ситуаций, сцен; мысленное перевоплощение в некие живые или неживые объекты [2].

Включение настоящей методики в работу с учащимися требует определенных условий, таких как, сокращение количества учащихся на занятии, создание особой атмосферы размещения (кабинета психологической разгрузки), знание педагогом основ психологического тренинга, владение инструментарием тренинговой работы. В основе процесса визуализации словесных образов в чувственные лежат эйдетические способности человека. Термин «эйдетика» был введен Э. Йеншем в 1930-е гг. На основе своих наблюдений ученый сделал вывод о сохранении четких следов информации в памяти человека.

Как показал собственный эксперимент, которым было охвачено около тысячи школьников 5-11-х классов, большинство представителей данной возрастной группы обладают способностями образного воспроизведения словесного (исключение составили дети с диагнозом «задержка психического развития» или те, у кого данный диагноз предполагаем). Наиболее ярким и четким является переход словесных обозначений в зрительные образы. При этом эйдетические способности, как и любые другие, развиваются, что способствует развитию образно-чувственного мышления, креативности мысли.

В ходе собственного эксперимента, проводимого автором в 1990-е гг. и первое десятилетие XXI в., для повышения качества исторического образования был разработан курс «История в образах и чувствах», в основе которого лежали идеи А.А. Вострикова. Содержание работы с учащимися строилось на основе их знаний истории, которые актуализировались на неосознаваемом уровне познания (интуиция, чувства, эмоции).

Приведем примеры ряда заданий по визуализации словесных установок:

- представьте орудия труда первобытного человека, оружие средневекового рыцаря...; услышьте звуки средневекового города, церковного колокола, залпы орудий...; почувствуйте, мысленно прикоснувшись, шкурку пушного зверя, китайский шелк... и т.п.;

- сеансы-путешествия в прошлое (алгоритм проведения сеанса должен соответствовать требованиям психологического тренинга);

- задания перевоплощения - в исторического деятеля, ремесленника, монаха и т.п. 
Специфика техники визуализации на неосознанном уровне заключается в свободе ассоциаций и перевоплощений, когда контроль сознательного снят, активизируются механизмы психики, благодаря которым значительно расширяется потенциал творческих способностей, активизируется работа правого полушария. Описанная техника визуализации имеет огромное значение для развития эмоционально-чувственной сферы личности.

Другая группа заданий предполагает разнообразные формы групповой активности: «создайте» скульптурный памятник участникам движения за реформу церкви; нарисуйте на ватмане коллективную картину «Мой путь к знаниям истории», не переговариваясь друг с другом (поймай мысль другого, поддержи и продолжи).

Анализируя собственный опыт, мы может утверждать, что данные варианты включения образов в изучение учебного предмета имеют огромный потенциал для его усвоения. Применение техники в условиях современных требований к образованию смогло бы повысить не только предметные, но и метапредметные (наглядно-образное мышление, творческое воображение, креативность) и личностные (развитие навыков рефлексии в процессе обсуждения образов - один из обязательных элементов занятий, построенных с опорой на теорию социально-коммуникативного тренинга) результаты освоения образовательной программы обучающимися.

Огромное значение техник визуализации доказано представителями педагогической науки, проверено многовековой практикой образования. В условиях компьютеризации рождаются новые возможности визуализации учебной информации. Критическое осмысление педагогом всего многообразия техник визуализации с учетом современных достижений науки, в том числе нейронаук, и целенаправленное использование их в организации учебного процесса будет способствовать повышению качества работы с учебной информацией обучающихся.

\section{Библиографический список / References}

1. Вахтеров В.П. Избранные педагогические сочинения / Отв. ред. М.Н. Скаткин; сост. Л.Н. Литвин, Н.Т. Бритаева. М., 1987. [Vakhterov V.P. Izbrannye pedagogicheskie sochineniya [Chosen pedagogical compositions]. L.N. Litvin, N.T. Britayeva (compilers); M.N. Skatkin (ed.). Moscow, 1987. (In Russ.)]

2. Востриков А.А. Культура мышления. Искусство работы с информацией с элементами педагогического мастерства. Ч. 1: Базовый курс интеллектуального развития и педагогического мастерства: Учебное пособие для пед. вузов. Томск; Одесса, 1995. [Vostrikov A.A. Kultura myshleniya. Iskusstvo raboty $\mathrm{s}$ informatsiey $\mathrm{s}$ elementami pedagogicheskogo masterstva. Ch. 1: 
Bazovyy kurs intellektualnogo razvitiya i pedagogicheskogo masterstva [Culture of thinking. Art of working with information with elements of pedagogical skill. Part 1: Basic course of intellectual development and pedagogical skills]. Tomsk; Odessa, 1995. (In Russ.)]

3. Гин А.А. ТРИЗ-педагогика: Учим креативно мыслить. M., 2016. [Gin A.A. TRIZ-pedagogika: Uchim kreativno myslit [TRIZ-pedagogy: We teach creative thinking]. Moscow, 2016. (In Russ.)]

4. Грегори Р. Глаз и мозг. Психология зрительного восприятия. URL: https:// knigogid.ru/books/1155688-glaz-i-mozg-psihologiya-zritelnogo-vospriyatiya (дата обращения: 14.01.2019). [Gregory R. Glaz i mozg [Eye and brain]. URL: https://knigogid.ru/books/1155688-glaz-i-mozg-psihologiya-zritelnogovospriyatiya. (In Russ.)]

5. Кларин М.В. Педагогические технологии в учебном процессе. Анализ зарубежного опыта. M., 1989. [Klarin M.V. Pedagogicheskie tekhnologii v uchebnom protsesse. Analiz zarubezhnogo opyta [Pedagogical technologies in the educational process. Analysis of foreign experience]. Moscow, 1989. (In Russ.)]

6. Коменский Я.А. Великая дидактика. М., 1939. [Comenius Y.A. Spicilegium Didacticum. Moscow, 1939 (In Russ.)]

7. Митрахович О.А. Формирование у старшеклассников умения работы с информацией: Автореф. дис. ... канд. пед. наук. М., 2012. [Mitrakhovich O.A. Formirovanie u starsheklassnikov umeniya raboty $\mathrm{s}$ informatsiey [Formation of information management skills of high school students]. PhD Diss. Moscow, 2012. (In Russ.)]

8. Окунев А.А. Развитие и реализация философско-педагогических идей «Французской группы Нового образования» (GFEN) в опыте современной школы России: Дис. ... канд. пед. наук. СПб., 2001. [Okunev A.A. Razvitie i realizatsiya filosofsko-pedagogicheskikh idey «Frantsuzskoy gruppy Novogo obrazovaniya» (GFEN) v opyte sovremennoy shkoly Rossii [Development and implementation of philosophical and pedagogical ideas of the "French Group of New Education" (Groupe Francais d'Education Nouvelle) in the experience of modern school of Russia]. PhD Diss. St. Petersburg, 2001. (In Russ.)]

9. Педагогические мастерские: «Франция-Россия»/ Под ред. Э.С. Соколовой. М., 1997. [Pedagogicheskie masterskie: "Frantsiya-Rossiya" [Pedagogical workshops: "France-Russia”]. E.S. Sokolova (ed.). Moscow, 1987 (In Russ.)]

10. Сорока О.Г., Васильева И.Н. Визуализация учебной информации // Университет педагогического самообразования. 2015. № 12. URL: http://elib. bspu.by/bitstream/doc/10693/1/Soroka_PS_12_2015.pdf (дата обращения: 14.01.2019). [Soroka O.G., Vasilieva I.N. Vizualizatsiya uchebnoy informatsii. Universitet pedagogicheskogo samoobrazovaniya. 2015. No. 12. URL: http:// elib.bspu.by/bitstream/doc/10693/1/Soroka_PS_12_2015.pdf (In Russ.)]

11. Фрайссин Ж. Матетика: трансдисциплинарная концепция обучения в цифровых сетях // Непрерывное образование: XXI век. 2016. № 1 (13). С. 1-25. [Frayssinhes J. Mathetics: transdisciplinary concept of learning in digital networks. Lifelong Education: The XXI Century. 2016. No. 1 (13). Pp. 1-25. (In Russ.)]

12. Хакимова Л.Г., Горлицына О.А. Визуализация учебного материала // Педагогический журнал Башкорстана. 2012. № 4 (41). С. 76-84. [Khakimova L.G., Gorlitsyna O.A. Training material visualization. Pedagogicheskiy zhurnal Bashkorstana. 2012. No. 4 (41). Pp. 76-84. (In Russ.)]. 
13. Шаталов В.Ф. Педагогическая проза. Архангельск, 1990 [Shatalov V.F. Pedagogicheskaya proza [Educational prose]. Arkhangelsk, 1990 (In Russ.)]

14. Челнокова Т.А. Метод синектики в преподавании истории и обществознания // Преподавание истории в школе. 2011. № 4. С. 31-36. [Chelnokova T.A. Method of Synectic in History and Social Science Teaching. Teaching history at school. 2011. No. 4. Pp. 31-36. (In Russ.)]

Статья поступила в редакцию 22.04.2019, принята к публикации 28.05.2019

The article was received on 22.04.2019, accepted for publication 28.05.2019

Сведения об авторе / About the author

Челнокова Татьяна Александровна - доктор педагогических наук; профессор кафедры теоретической и инклюзивной педагогики, Казанский инновационный университет им. В.Г. Тимирясова

Tayana A. Chelnokova - Dr. Pedagogy Hab.; professor at the Department of Theoretical and Inclusive Pedagogy, Kazan Innovative University named after V.G. Timiryasov

E-mail: nfuka@zel.ieml.ru 